\title{
Acute epiglottitis in a fully immunized child
}

Marasinghe $\mathrm{DT}^{1}$, Panditha $\mathrm{KKS}^{2}$,Jayaweera $\mathrm{JMRG}^{3}$

${ }^{1}$ Registrar in Paediatrics, Avissawella Base Hospital, Sri Lanka

${ }^{2}$ Consultant Paediatrician, Avissawella Base Hospital, Sri Lanka

${ }^{3}$ Consultant ENT Surgeon, Avissawella Base Hospital, Sri Lanka

\section{Abstract}

Acute epiglottitis in children became a rare entity after introduction of the conjugate Haemophilus influenzae type $\mathrm{b}(\mathrm{Hib})$ vaccine $^{1}$. However, physicians must be aware that epiglottitis may result from vaccine failures or from infection with other pathogenic organisms. Vaccinated children with epiglottitis present in a similar fashion to those who are not vaccinated ${ }^{2}$. The following is a case of a previously healthy and immunized child who presented to paediatric ward and ultimately diagnosed as epiglottitis.

\section{Keywords}

Acute Epiglottitis, Haemophilus influenzae

Copyright: (c) 2019 Marasinghe D T et al.

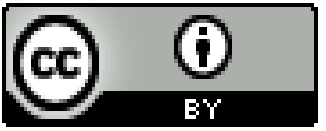

This is an open access article distributed under the Creative Commons Attribution License (CCBY), This license lets others distribute, remix, tweak, and build upon the work, even commercially, as long as they credit the original author for the creation.

Funding: None

Competing interest: None

Correspondence: Marasinghe D T

Accepted Date : 12/2/2019

Published Date : 2/3/2019 


\section{Case report}

An infrequent wheezer, fully immunized 8-year-old boy presented with fever, sore throat,difficulty in swallowing, on the background of 2 days of rhinorrhoea and cold. On presentation he had a respiratory rate of 32 breaths per minute, a heart rate of 132 beats per minute, a pulse oxygen saturation $\left(\mathrm{SpO}_{2}\right)$ of $99 \%$ in room air, and a temperature of $103^{\circ} \mathrm{F}$. He was ill-looking withno respiratory distress butrefused to take oral medications and kept his neck extended.

Examination revealed an erythematous inflamed oropharynx with no cervical lymphadenopathy. Hehad a few rhonchion auscultation bilaterally, without stridor. The rest of the physical examination was unremarkable. A dose of nebulized salbutamol was given without clinical improvement. Laboratory analysis including a complete blood count was notable for a white blood cell count of $16.49 \times 10^{3}$ with $91 \%$ neutrophils and a CRP of 219.9. Radiograph of his neck was obtained, which was inconclusive. Ultrasound neck suggested a retropharyngeal abscess with 2.5 $\mathrm{cm} \times 3 \mathrm{~cm} \times 0.5 \mathrm{~cm}$ collection between larynx and spine and blood cultures were drawn. The Child was started on intravenous cefotaxime and clindamycin. An ENT surgeon was referred to immediately, and an incision anddrainage planned.

At the operation theatre,examination under anaesthesia revealed no retropharyngeal abscess but asignificant oedema and erythema of the epiglottis extending down the bilateral aryepiglottic folds involving the arytenoids.A diagnosis of acute epiglottitis was made. (Fig 1)

Bronchoscope assessisted tracheal intubationwas done and the child was admitted to the ICU for further monitoring. He recovered within 48 hours without other systemic complications. His blood culture was subsequently positive for Haemophilus Influenzae.

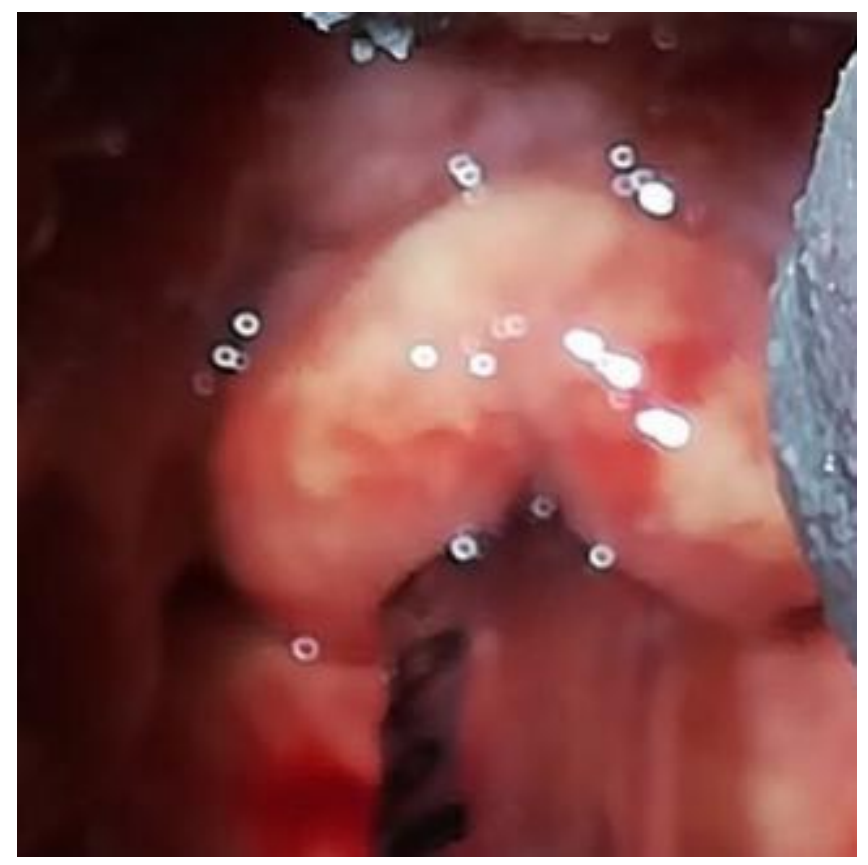

Fig 1

View on examination under anaesthesia

\section{Discussion}

Upper airway emergencies in a febrile child tend to have infectious origins, with croup, bacterial tracheitis, epiglottitis, and retropharyngeal abscess as the leading aetiologies. Epiglottitis is a sporadic illness among children in the post-Hib vaccination era, with Hib as the leading etiologic 
agent, primarily in unvaccinated, immune-compromised, and adult patients ${ }^{[3]}$. Despite the marked decrease in invasive Hib disease, caregivers should continue to consider the pathogen $H$ influenzae as a possible aetiology in acute epiglottitis, with a $\beta$-lactam/ $\beta$-lactamase inhibitors or third-generation cephalosporin being first-line treatment.Vaccine failure is defined as a case occurring after at least two doses of vaccine given in the first year of life or after a single vaccination given to children at the age of 12 months or more ${ }^{[4]}$. Vaccine failure may be related in part to genetic factors, and that most vaccinated children in whom Haemophilus influenzae disease develops have deficient antibody responses to the type b polysaccharide despite normal serum concentrations of immunoglobulin and normal antibody responses to tetanus toxoid ${ }^{[5]}$.

\section{References}

1. Keyser J, Derkay C. Haemophilus influenzae type B epiglottitis after immunization with HbOC conjugate vaccine. American Journal of Otolaryngology. 1994;15(6):436-443.

2. Gorga S, Gilsdorf J, Mychaliska K. Haemophilus influenzae Serotype f Epiglottitis: A Case Report and Review. Hospital Pediatrics. 2016;:hpeds.2015-0241.

3. Baird S, Marsh P, Padiglione A, Trubiano J, Lyons B, Hays A et al. Review of epiglottitis in the post Haemophilus influenzae type-b vaccine era. ANZ Journal of Surgery. 2018.

4. Hemophilus Influenzae Type B Disease in Children Vaccinated with Type B Polysaccharide Vaccine | NEJM [Internet]. New England Journal of Medicine. 2018 [cited 18 October 2018]. Available from: https://www.nejm.org/doi/full/10.1056/NEJM198612183152505

5. Anglaret X, Buissonnière R, Duval P, Ménager C. INVASIVE HAEMOPHILUS INFLUENZAE DISEASE OF MELANESIAN AND CAUCASIAN CHILDREN IN NEW CALEDONIA. The Pediatric Infectious Disease Journal. 1993;12(10):888. 